\title{
In-plane Anisotropy of Selective Laser Melted Stainless Steel: The Importance of the Rotation Angle Increment and the Limitation Window
}

\author{
Leonhard Hitzler ${ }^{\mathrm{a}}$, Johann Hirsch ${ }^{\mathrm{b}}$, Josef Tomas ${ }^{\mathrm{b}}$, Markus Merkel ${ }^{\mathrm{b}}$, \\ Wayne Hall ${ }^{\mathrm{a}}$, Andreas Öchsner ${ }^{\mathrm{a}}$
}

a Griffith School of Engineering, Griffith University, Gold Coast Campus, Southport 4222, Australia

b Faculty of Mechanical Engineering and Material Science, Aalen University of Applied Sciences, 73430

Aalen, Germany

Keywords: Tensile Strength, Stiffness, Build Environment, Inert Gas Flow, Irradiation Pattern, Scan Strategy, $1.4404,316 \mathrm{~L}$

\begin{abstract}
The thorough description of the influence of the process conduct in powder-bed based additive manufacturing on the mechanical properties of the fabricated components represents an ongoing challenge. A recent investigation highlighted that a minor safety feature, such as limiting the range of possible laser beam movements to avoid interactions between the irradiation and emerging smoke and weld splashes, can cause a noteworthy alteration of the mechanical properties. In this study, the tensile characteristics of selective lasermelted stainless steel $(1.4404,316 \mathrm{~L})$ fabricated with two different process conducts were investigated, both of which yielded similar relative densities and surface hardness values. It was found that besides these two characteristics the tensile strength (yield and ultimate tensile strength) remained stable, whereas the linear elastic properties, as well as the breaking elongation, exhibited great fluctuations. The Young's modulus in the buildplane ranged from 151 to $208 \mathrm{GPa}$, and the breaking elongation ranged, respectively, from $33 \%$ to $43 \%$. Furthermore, it has been found that this anisotropy is an adjustable characteristic and can be modified via two parameters, the rotation angle increment of the irradiation pathways between successive layers and their total admissible range, also referred to as the limitation window.
\end{abstract}




\section{Introduction}

Additive Manufacturing (AM) techniques utilizing metals, and especially those employing the full melting of the raw material, represent powerful freeform fabrication methods, capable of generating directly deployable components with excellent mechanical properties ${ }^{1}$. Within the range of techniques available, this investigation focusses on the Selective Laser Melting (SLM), also known as Laser Beam Melting (LBM). This particular process unites the opportunities to realize complex geometries and shapes with good accuracy and, moreover, allows altering the surface characteristics and material properties via processing parameters ${ }^{2-4}$. The latter two points are of outstanding value for the application in the medical sector. For example, the ability to design rough and porous surfaces, which promote bone ingrowth and increase the contact surface area, was proven to lower the likelihood of implant rejections ${ }^{5-7}$. Moreover, the opportunity to adjust the stiffness via the deliberate fabrication of porous structures, or via the process conduct in the case of fully dense components, can be utilized to enhance the compatibility with the body and to mitigate stress-shielding effects ${ }^{8-10}$. The alterations of the stiffness, or respectively the adjustment of the elastic material behaviour, via a designed porosity or via the relative density are common and well-known traits ${ }^{11-14}$. Less investigated are the alterations in fully-dense components via the processing parameters: Niendorf, Leuders ${ }^{15}$ studied the volatility of the tensile characteristics of stainless steel in dependency to the laser power. It was found that the utilization of a high power laser source (up to $1000 \mathrm{~W}$ ) resulted in a noteworthy decrease of both the elastic modulus and the yield strength, coupled with a small decrease in the ultimate tensile strength, but also in a drastic gain in ductility. Moreover, the deliberate and controllable inclusion of inhomogeneity was presented, utilizing multiple laser sources with different power levels in a single machine ${ }^{16}$. However, this alteration mechanism is most effective to influence the properties along the build direction, due to its foundation being primarily the epitaxial grain growth of stainless steel, which, process-related, is most emphasised in the direction of the heat source, i.e. perpendicular to the layers ${ }^{17}$. In general, the layer-wise fabrication approach yields to an anisotropic material behaviour. The stiffness, the mechanical strength and ductility, as well as the fracture toughness of selective laser melted components are higher in load scenarios parallel to the layers, opposed to perpendicular to it ${ }^{18,19}$. The emphasis on this, as well as the progression of the characteristics in between these distinct orientations, commonly referred to as polar angle dependency, was previously shown to be highly material-dependent ${ }^{20}$. However, whilst pursuing the study on the polar angle dependency an anisotropic behaviour in the 2D-plane of the layer was noticed. Breaking down the 2D layer into distinct, process related, translational motions, i.e. the 
recoating movement $(\mathrm{x})$ and the inert gas flow (y), tensile samples fabricated in these two directions were found to differ in their Young's modulus by as much as 30\%. Interestingly, the encountered in-plane anisotropy was restricted to the linear-elastic properties (i.e. Young's modulus and Poisson's ratio) and the breaking elongation, whereas the tensile strength, both the yield and ultimate tensile strength, remained stable on the other hand. In general, the anisotropic effects occurring in-plane are less pronounced as the directional dependencies in respect to the polar angle ${ }^{20}$. Kunze, Etter ${ }^{21}$ found in their study on additively manufactured Inconel that the Young's modulus was dependent on the build and scanning direction, with its minima being parallel to the build direction and in the direction of the scan vectors. Sehrt and Witt ${ }^{22}$, on the other hand, described the in-plane anisotropy as negligible in their study. However, the in-plane dependencies are highly influenced by the chosen scan strategy, or in other words, the process conduct of the assembling schemata applied, which discretises an entire component as layered sequence of individual scan tracks. Thus, the presence of in-plane anisotropy is dependent on the individual manufacturing settings, allowing it to be adjustable at will to embed a deliberate, customised anisotropy in fully-dense parts. Sehrt ${ }^{23}$ reported that a $67^{\circ}$ rotation increment between layers led to a constant in-plane Young's modulus. Thijs, Kempen ${ }^{24}$ documented a significantly reduced texture in AlSi10Mg when the scan vectors of consecutive layers are rotated by $90^{\circ}$. Moreover, it was shown that subdivisions with varying rotation angles within one single layer in a chessboard-like arrangement have no noteworthy benefit over the simpler line scanning approach. In addition, it was emphasised that for the line scanning approach the choice between either uni- or bidirectional scan tracks does not alter the texture. In terms of the line scanning approach, there is one more parameter to consider, i.e. the length of the scan tracks. The selection of this parameter is a compromise between: the risk of occurring cracks and deformations due to induced residual stresses, emphasised by long scan tracks; and the risk of promoting keyhole pores, or voids in general, as their likelihood increases with the number of single scan tracks required, which is directly related to the size of the individual scan track ${ }^{25,26}$. As a result, the most common and recommended approach to tackle this issue is to choose a medium to large scan track lengths to lower the number of total voids, likely to occur on the scan track start and end points, and to counteract the arising residual stresses via elevated preheating temperatures in the build chamber $^{27,28}$.

Within this study, the emphasis of the induced in-plane anisotropy on varying line scanning parameter sets is investigated on the example of stainless steel. The utilised parameter sets are based on recommended settings from the machine manufacturer and rely on the line scanning approach, but differ in terms of the rotation angle increment, the scan track length and the selection of the limitation window. The latter is an in-build precaution 
feature, limiting the allowable range of scan directions to prevent interactions between the laser irradiation and particles in the inert gas stream ${ }^{29}$. It is believed that this parameter contributed to the encountered in-plane anisotropy in our previous study ${ }^{20}$. This work is also aimed to explain possible deviations found across comparable studies, and possible changes in the properties of manufactured components reasoned in software updates.

\section{Methodology}

\subsection{Manufacturing conditions}

In this study, a SLM 280HL machine (SLM Solutions GmbH, Lübeck, Germany) equipped with a 400 W Ybfibre-laser was utilized. It features an available build space of $280 \times 280 \times 320 \mathrm{~mm}^{3}$ and includes a preheating system, integrated in the mounting plate underneath the substrate. Two standard parameter sets, recommended by the machine supplier for the processing of the low carbon stainless steel type EN 1.4404, US 316L (also known as $\mathrm{X} 2 \mathrm{CrNiMo17-12-2)}$ were utilized (Table 1) for the fabrication of the samples. The metal powder was supplied by SLM Solutions and had the following properties; a mean particle diameter of $35.5 \mu \mathrm{m}$ and an apparent powder density of $3.85 \mathrm{~g} / \mathrm{cm}^{3}$. Its detailed properties, together with the resulting surface roughness characteristics in dependency to the varying contour irradiation settings and in regard to the distinct position in the build space, have been addressed in a previous study ${ }^{30,31}$.

A schematic depiction of the involved parameters in the layer-wise generation process, comprising single scan tracks with layer-dependent alterations, is provided in Figure 1. Based on the differing settings on the limitation window and the rotation angle increment the arising stacking schemata vary. For the cases at hand, the layered scan vector arrangements as outlined in Table 2 result. The start condition is the lower increment border of the limitation window equalling the initial track vector direction, with the scan track vectors placed in altering perpendicular directions. The track vector direction is continuously changed by constantly adding the rotation increment after every layer, until the upper limitation window is exceeded. In this case, the new vector track is defined by the lower limitation window border plus the former excess. From there, the pattern continues by adding the rotation increment after every layer until the upper limit is exceeded again.

Flat tensile specimens, in accordance to the German standard DIN 50125:2009-0 $7^{32}$, type E 5 x 10 x 40, were fabricated in two distinct orientations (Figure 2), respectively in $\mathrm{x}$ and in $\mathrm{y}$ direction. Hereby, the width of the 
samples represents the build direction and for the desired investigation of the in-plane anisotropy no inclination relative to the substrate plate was considered, i.e. the polar angle for all configurations equals zero (Table 3). Details about the influence of the inclination angle to the substrate plate can be found elsewhere ${ }^{20}$. The specimens were fabricated with an oversize of $0.4 \mathrm{~mm}$ and machined to their final shape. Hence, the deviations in the contour irradiation settings can be truly neglected and were only of relevance for the previously mentioned surface quality investigations.

Table 1: Parameter sets utilized for fabrication; differentiated between constant and case dependent settings, i.e. parameter set 1 and 2

\begin{tabular}{|c|c|c|c|c|c|c|}
\hline $\begin{array}{c}\text { Parameter } \\
\text { set }\end{array}$ & Parameter & $\begin{array}{c}\text { Scan speed } \\
{[\mathrm{mm} / \mathrm{s}]}\end{array}$ & $\begin{array}{c}\text { Laser } \\
\text { power [W] }\end{array}$ & $\begin{array}{c}\text { Hatch } \\
\text { distance }[\mathrm{mm}]\end{array}$ & $\begin{array}{l}\text { Rotation angle } \\
\text { increment }\left[{ }^{\circ}\right]\end{array}$ & $\begin{array}{c}\text { Energy density } \\
{\left[\mathrm{J} / \mathrm{mm}^{3}\right]}\end{array}$ \\
\hline \multirow{5}{*}{1} & Core & 750 & 175 & 0.12 & 90 & 64.8 \\
\hline & Contour & 550 & 100 & 0.09 & - & 67.3 \\
\hline & Support & 650 & 100 & - & - & - \\
\hline & \multicolumn{6}{|c|}{ Scan vector length of $7.5 \mathrm{~mm}$} \\
\hline & \multicolumn{6}{|c|}{ Limitation window of $160^{\circ}$, respectively $\pm 80^{\circ}$ to the $y$-axis } \\
\hline \multirow{5}{*}{2} & Core & 800 & 200 & 0.12 & 33 & 69.4 \\
\hline & Contour & 400 & 100 & 0.09 & - & 92.6 \\
\hline & Support & 875 & 200 & - & - & - \\
\hline & \multicolumn{6}{|c|}{ Scan vector length of $10 \mathrm{~mm}$} \\
\hline & \multicolumn{6}{|c|}{ Limitation window of $90^{\circ}$, respectively $\pm 45^{\circ}$ to the $y$-axis } \\
\hline \multirow{4}{*}{$\begin{array}{l}\text { Constant } \\
\text { settings }\end{array}$} & \multicolumn{6}{|c|}{ Layer thickness of $30 \mu \mathrm{m}$} \\
\hline & \multicolumn{6}{|c|}{ Mounting plate temperature of $200^{\circ} \mathrm{C}$} \\
\hline & \multicolumn{6}{|c|}{ Nitrogen is employed as the inert gas } \\
\hline & \multicolumn{6}{|c|}{ Contour is irradiated first, followed by the core, utilising the bidirectional line scanning strategy } \\
\hline
\end{tabular}

* A comprehensive explanation of the individual parameters and the manufacturing process itself can be found elsewhere ${ }^{1}$. 
Table 2: Layer stacking, track vector and scan vector orientations

\begin{tabular}{|c|c|c|c|c|}
\hline & \multicolumn{2}{|c|}{ Parameter set 1} & \multicolumn{2}{|c|}{ Parameter set 2} \\
\hline Layer & Track vector angle & Scan vector angle & Track vector angle & Scan vector angle \\
\hline $\mathbf{n}$ & $\begin{array}{c}\text { [bottom increment } \\
\text { limitation border] }=100^{\circ}\end{array}$ & $\begin{array}{l}\text { [track vector angle] } \\
\pm 90^{\circ}=10^{\circ} ; 190^{\circ}\end{array}$ & $\begin{array}{c}\text { [bottom increment } \\
\text { limitation border }]=135^{\circ}\end{array}$ & $\begin{array}{l}\text { [track vector angle] } \\
\pm 90^{\circ}=45^{\circ} ; 225^{\circ}\end{array}$ \\
\hline $\mathbf{n}+1$ & $\begin{array}{c}\text { [previous track vector } \\
\text { angle] }+ \text { [rotation angle } \\
\text { increment }]=100^{\circ}+90^{\circ} \\
=190^{\circ}\end{array}$ & $\begin{array}{l}\text { [track vector angle] } \\
\pm 90^{\circ}=100^{\circ} ; 280^{\circ}\end{array}$ & $\begin{array}{c}\text { [previous track vector } \\
\text { angle }]+[\text { rotation angle } \\
\text { increment }]=135^{\circ}+33^{\circ}= \\
168^{\circ}\end{array}$ & $\begin{array}{l}\text { [track vector angle] } \\
\pm 90^{\circ}=78^{\circ} ; 258^{\circ}\end{array}$ \\
\hline $\mathrm{n}+2$ & $\begin{array}{l}\text { would be outside the } \\
\text { limitation window!, thus: } \\
\text { [previous track vector } \\
\text { angle] }+ \text { [rotation angle } \\
\text { increment] }- \text { [top } \\
\text { increment limitation } \\
\text { border] }+ \text { [bottom } \\
\text { increment limitation } \\
\text { border] }=190^{\circ}+90^{\circ} \text { - } \\
260^{\circ}+100^{\circ}=120^{\circ} \\
\end{array}$ & $\begin{array}{l}\text { [track vector angle] } \\
\pm 90^{\circ}=30^{\circ} ; 210^{\circ}\end{array}$ & $\begin{array}{c}\text { [previous track vector } \\
\text { angle }]+[\text { rotation angle } \\
\text { increment }]=168^{\circ}+33^{\circ}= \\
201^{\circ}\end{array}$ & $\begin{array}{l}{[\text { track vector angle] }} \\
\pm 90^{\circ}=111^{\circ} ; 291^{\circ}\end{array}$ \\
\hline $\mathbf{n}+\mathbf{3}$ & $\begin{array}{c}\text { [previous track vector } \\
\text { angle }]+[\text { rotation angle } \\
\text { increment }]=120^{\circ}+90^{\circ} \\
=210^{\circ}\end{array}$ & $\begin{array}{l}\text { [track vector angle] } \\
\pm 90^{\circ}=120^{\circ} ; 300^{\circ}\end{array}$ & $\begin{array}{l}\text { would be outside the } \\
\text { limitation window!, thus: } \\
\text { [previous track vector } \\
\text { angle] }+ \text { [rotation angle } \\
\text { increment] }- \text { [top } \\
\text { increment limitation } \\
\text { border] }+ \text { [bottom } \\
\text { increment limitation } \\
\text { border] }=201^{\circ}+33^{\circ} \text { - } \\
225^{\circ}+135^{\circ}=144^{\circ}\end{array}$ & $\begin{array}{l}\text { [track vector angle] } \\
\pm 90^{\circ}=54^{\circ} ; 234^{\circ}\end{array}$ \\
\hline$n+4$ & $\begin{array}{l}\text { would be outside the } \\
\text { limitation window!, thus: } \\
\text { [previous track vector } \\
\text { angle] + [rotation angle } \\
\text { increment] }- \text { [top } \\
\text { increment limitation } \\
\text { border] }+ \text { [bottom } \\
\text { increment limitation } \\
\text { border] }=210^{\circ}+90^{\circ} \text { - } \\
260^{\circ}+100^{\circ}=140^{\circ}\end{array}$ & $\begin{array}{l}\text { [track vector angle] } \\
\pm 90^{\circ}=50^{\circ} ; 230^{\circ}\end{array}$ & $\begin{array}{c}\text { [previous track vector } \\
\text { angle }]+[\text { rotation angle } \\
\text { increment }]=144^{\circ}+33^{\circ}= \\
177^{\circ}\end{array}$ & $\begin{array}{l}\text { [track vector angle] } \\
\pm 90^{\circ}=87^{\circ} ; 267^{\circ}\end{array}$ \\
\hline$n+5$ & $\begin{array}{c}\text { [previous track vector } \\
\text { angle] }+ \text { [rotation angle } \\
\text { increment }]=140^{\circ}+90^{\circ} \\
=230^{\circ}\end{array}$ & $\begin{array}{l}\text { [track vector angle] } \\
\pm 90^{\circ}=140^{\circ} ; 320^{\circ}\end{array}$ & $\begin{array}{c}\text { [previous track vector } \\
\text { angle }]+[\text { rotation angle } \\
\text { increment }]=177^{\circ}+33^{\circ}= \\
210^{\circ}\end{array}$ & $\begin{array}{l}{[\text { track vector angle] }} \\
\pm 90^{\circ}=120^{\circ} ; 300^{\circ}\end{array}$ \\
\hline$n+6$ & $\begin{array}{l}\text { would be outside the } \\
\text { limitation window!, thus: } \\
\text { [previous track vector } \\
\text { angle] }+ \text { [rotation angle } \\
\text { increment] }- \text { [top } \\
\text { increment limitation } \\
\text { border] }+ \text { [bottom } \\
\text { increment limitation } \\
\text { border] }=230^{\circ}+90^{\circ} \text { - } \\
260^{\circ}+100^{\circ}=160^{\circ}\end{array}$ & $\begin{array}{l}\text { [track vector angle] } \\
\pm 90^{\circ}=70^{\circ} ; 250^{\circ}\end{array}$ & $\begin{array}{l}\text { would be outside the } \\
\text { limitation window!, thus: } \\
\text { [previous track vector } \\
\text { angle] }+ \text { [rotation angle } \\
\text { increment] }- \text { [top } \\
\text { increment limitation } \\
\text { border] }+ \text { [bottom } \\
\text { increment limitation } \\
\text { border] }=210^{\circ}+33^{\circ}- \\
225^{\circ}+135^{\circ}=153^{\circ}\end{array}$ & $\begin{array}{l}\text { [track vector angle] } \\
\pm 90^{\circ}=63^{\circ} ; 243^{\circ}\end{array}$ \\
\hline$\cdots$ & $\begin{array}{r}\text { to be conti } \\
\text { first repetition occurs afte } \\
\text { there on after ev }\end{array}$ & $\begin{array}{l}\text { ued; } \\
\text { the } 18 \text { th layer, from } \\
16 \text { layers }\end{array}$ & $\begin{array}{l}\text { to be conti } \\
\text { first repetition occurs after } \\
\text { there on after eve }\end{array}$ & $\begin{array}{l}\text { hed; } \\
30 \text { layers }\end{array}$ \\
\hline
\end{tabular}


a)

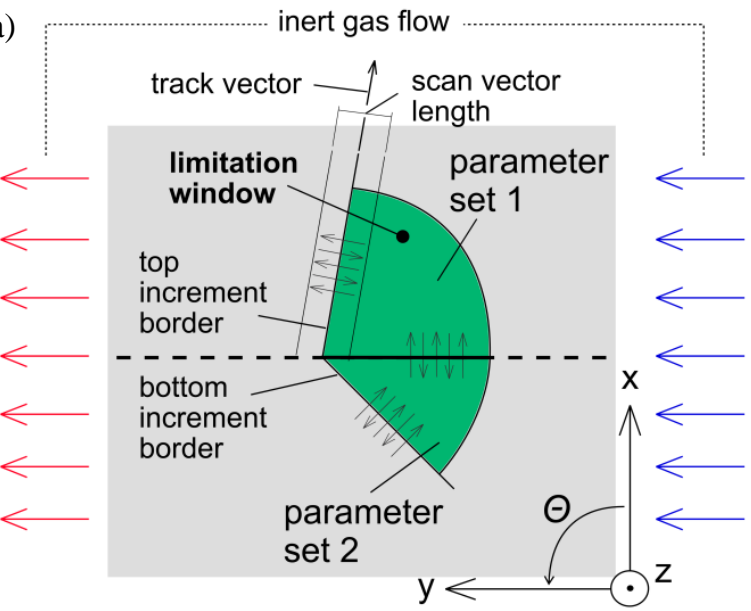

b)

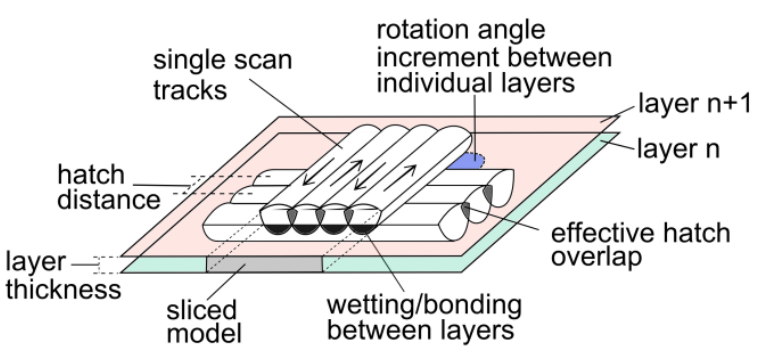

Figure 1: Scan strategy and influencing parameters: a) Definition of the limitation window; b) parameters and layer wise generation, depicts a $90^{\circ}$ rotation angle increment; adapted from ${ }^{1,29}$

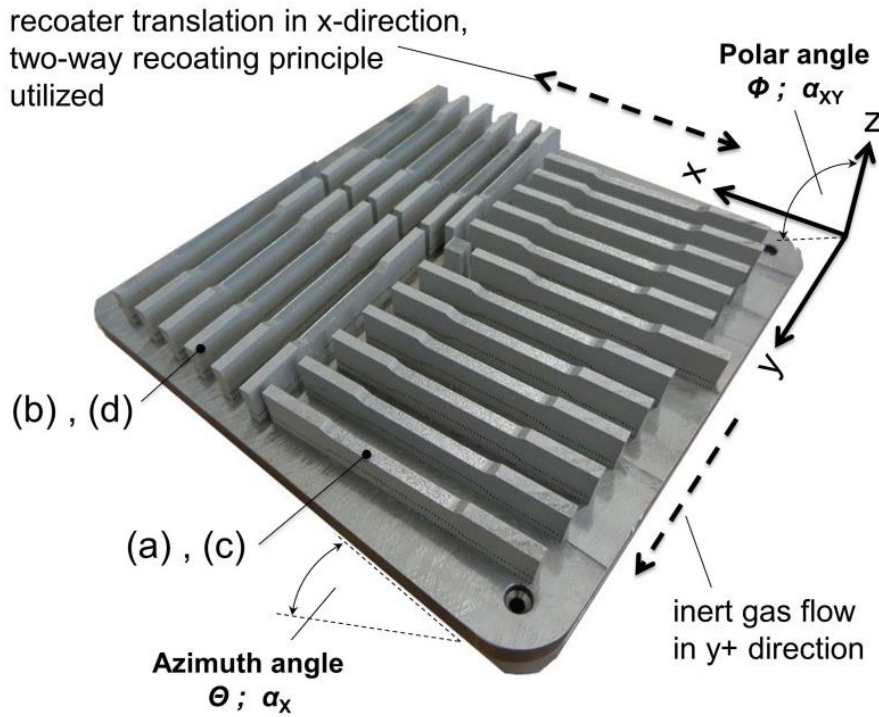

Figure 2: Fabricated stainless steel samples; two identical build jobs with differing parameter sets, adapted from 20,30

Table 3: Summary of positioning details for all considered configurations and grouping of individual manufacturing jobs

\begin{tabular}{|c|c|c|}
\hline Config. & Azimuth angle* $\boldsymbol{\Theta} ; \boldsymbol{\alpha}_{\mathbf{X}}\left[^{\circ}\right]$ & Parameter set \\
\hline (a) & 0 & 1 \\
\hline (b) & 90 & 1 \\
\hline (c) & 0 & 2 \\
\hline (d) & 90 & 2 \\
\hline
\end{tabular}

*Slight deviations from $0^{\circ}$ and $90^{\circ}$ angles were introduced for the azimuth angle to improve the recoating process by ensuring that its blade does not abruptly hit an entire sample edge at once. 


\subsection{Relative density and hardness}

The relative density and the surface hardness were determined in order to confirm the consistency in between the two build job and to ensure their comparability. The relative densities were determined via the Archimedes principle, i.e. weighing the samples in air and in water and determine their density, which then was compared to the theoretical density of the bulk base 1.4404 . The surface hardness was measured with a Reicherter KF hardness tester (Reicherter Georg GmbH Co Kg, Esslingen, Germany) on the clamping areas of the tensile specimens. The measurements were undertaken in accordance to the DIN EN ISO 6507-2 standard ${ }^{33}$. Since the preliminary investigations suggested that the fluctuations in the surface hardness are rather minimal in comparison to the anisotropic effects, the focus within this investigation were the tensile characteristics ${ }^{20}$.

\subsection{Tensile testing}

The destructive tests were performed at room temperature on a tensile testing machine (Zwick/Roell, Ulm, Germany) with an inbuilt extensometer, which initial distance was set to a $50 \mathrm{~mm}$ gauge length. The maximum load for this machine is $100 \mathrm{kN}$ and the testing procedure was carried out in accordance to the German standard DIN EN ISO 6892-1:2016 ${ }^{34}$ with a constant cross-head speed of $5 \mathrm{~mm} / \mathrm{min}$. The integrated variable extensometer has an uncertainty of $0.02 \%$, and the load cell (type KTN-Z/D, GTM Testing and Metrology GmbH, Bickenbach, Germany), has an uncertainty of $0.2 \%$.

\section{Results and discussion}

\subsection{Coherence of build jobs}

Prior to the tensile tests, the relative densities of the specimens were determined via the Archimedes principle. There was no noticeable deviation amongst the two batches and all samples had a consistent relative density greater than 99\%. Moreover, the surface hardness, obtained on the machined samples, was consistent, ranging from $236 \mathrm{HV} 30$ to $239 \mathrm{HV} 30$ for the parameter set 1 and, respectively, $227 \mathrm{HV} 30$ to $234 \mathrm{HV} 30$ for the parameter set 2 .

\subsection{Tensile testing}

The samples exhibited arbitrary points of failure along their prismatic gauge length, indicating that there is no evidence present for locally induced weak spots which could systematically falsify the results. The samples 
exhibited remarkably stable results regarding their yield and ultimate tensile strength, with fluctuations below 25 $\mathrm{MPa}$ across the configurations. The averaged results of the tensile test, as well as the according standard deviations, are presented in Table 4 and the individual stress-strain graphs are summarised in Figure 3. All configurations revealed a remarkable strength with their yield strength exceeding the minimum requirement of the ultimate tensile strength of the bulk base material. Given the consistency of the strength results across the samples fabricated with varying scan track orientations, it can be concluded that the following holds true for inplane directional dependencies: The tensile strength is an isotropic characteristic, whilst the stiffness and elongation at failure are volatile to the scan strategy settings and can exhibit an anisotropic behaviour. On a side note, this differs from the polar angle dependency, which affects all tensile characteristics ${ }^{18,20}$.

In regard to the evident dependencies based on the azimuth angle, the samples fabricated with the parameter set 1 showed a less emphasised directional dependency, with configuration (b) almost equalling the Young's modulus of the bulk base material. The configuration (d) samples even exceeded this nominal Young's modulus, but the parameter set 2 lowered the Young's modulus perpendicular to it (configuration (c)). Given this, it can be concluded that the tendency is coherent; both parameter sets revealed a higher stiffness in y-direction. Based on the applied scan vector patterns it appeared that the excluded direction, i.e. scan track vectors placed parallel to the $y$-axis, led to an increased stiffness in this direction. Considering the results for the breaking elongation, the obtained results showed an isotropic behaviour for the parameter set 1 . However, in the case of the parameter set 2 deviations greater than $20 \%$ were evident. Yet, there is no clear correlation of the occurred anisotropy regarding the stiffness and breaking elongation. For the parameter set 2 the stiffer and more ductile direction coincided, whereas for the parameter set 1 the difference in ductility is within the margin of error, whilst there is a distinct predominant direction for the Young's modulus present.

Table 4 Averaged results for the tensile properties of 1.4404; partially adapted from ${ }^{20}$

\begin{tabular}{|c|c|c|c|c|c|c|c|c|}
\hline \multirow{2}{*}{ Config. } & \multicolumn{2}{|c|}{$\begin{array}{c}\text { Young's modulus } \\
\boldsymbol{E}[\mathbf{G P a}\end{array}$} & \multicolumn{2}{c|}{$\begin{array}{c}\text { Yield strength } \\
\boldsymbol{R}_{\mathbf{p 0 . 2}}[\mathbf{M P a}]\end{array}$} & $\begin{array}{c}\text { Ultimate tensile } \\
\text { strength } \boldsymbol{R}_{\mathbf{m}}[\mathrm{MPa}]\end{array}$ & \multicolumn{2}{c|}{$\begin{array}{c}\text { Elongation at } \\
\text { failure } \boldsymbol{A}_{\mathbf{t}}[\%]\end{array}$} \\
\cline { 2 - 10 } & Average & STDEV & Average & STDEV & Average & STDEV & Average & STDEV \\
\hline (a) & 167 & 16 & 522 & 7 & 636 & 6 & 36.8 & 1.1 \\
\hline (b) & 196 & 21 & 535 & 8 & 647 & 8 & 36.0 & 1.3 \\
\hline (c) & 151 & 26 & 517 & 7 & 634 & 7 & 33.2 & 0.3 \\
\hline (d) & 208 & 24 & 539 & 3 & 644 & 3 & 42.7 & 0.8 \\
\hline $\begin{array}{c}\text { bulk base } \\
1.4404\end{array}$ & \multicolumn{2}{|c|}{200} & \multicolumn{2}{|c|}{$200-240$} & $500-700$ & & 40 \\
\hline
\end{tabular}




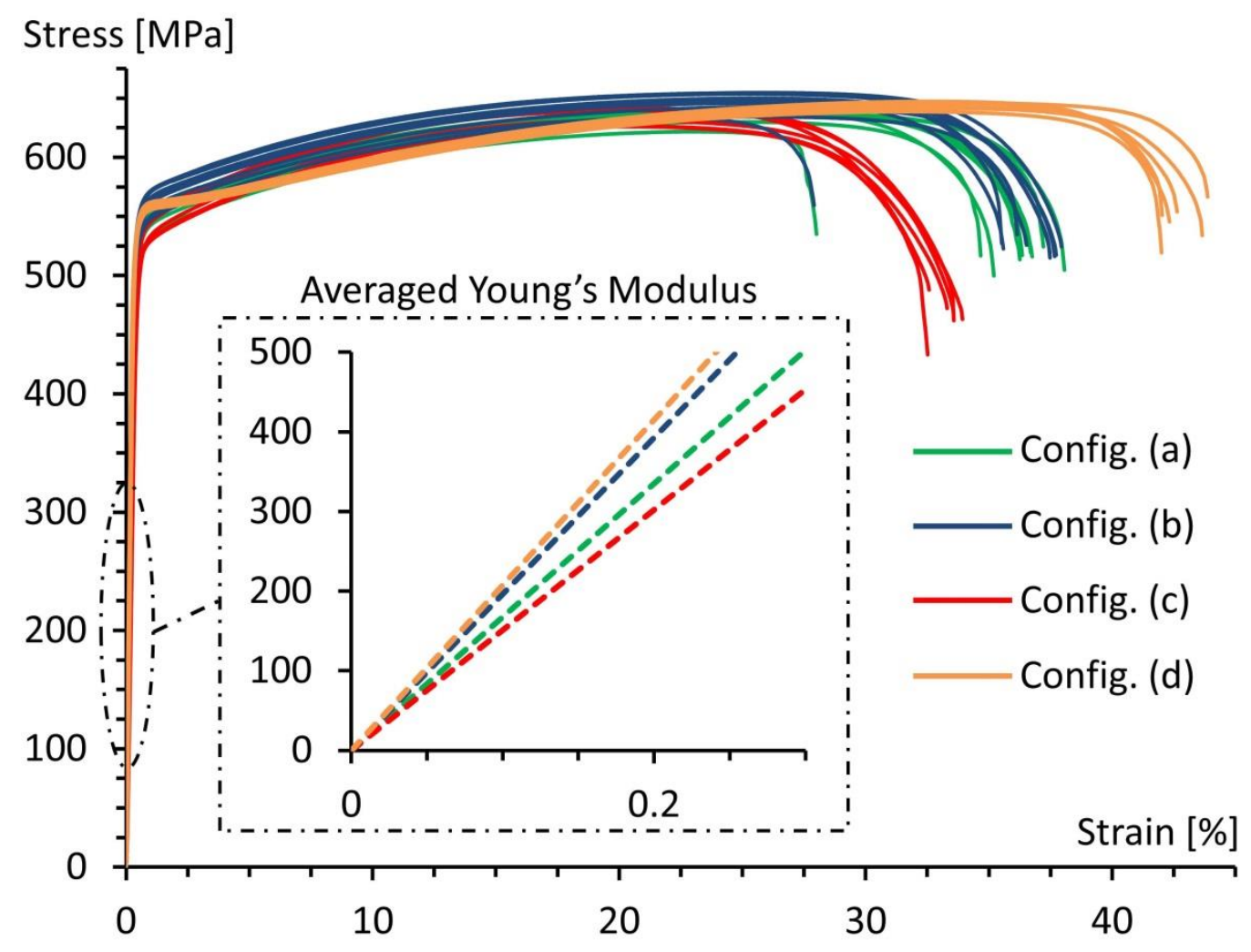

Figure 3: Tensile stress-strain diagrams and magnification of the anisotropy in the linear elastic range

\subsection{Restrictions of the applied stacking schemata}

With a closer look at the applied calculation approach for the stacking schemata (Table 2) it can be said that the full limitation window cannot truly be utilized. After the initial start at the bottom increment border (Figure 1) this orientation is not passed through again. With the applied standard parameter sets a stable pattern with a distinct repetition rate sets in and renders the consideration of the excess in the calculation, which is aimed to achieve a continuously rotating pattern, partially counterproductive. In the constantly repeated patterns the effective limitation windows ranges for the parameter set 1 from $110^{\circ}$ to $250^{\circ}$ and for the parameter set 2 from $138^{\circ}$ to $225^{\circ}$. Hence, the narrowing effect of the limitation window mainly influenced parameter set 1 , via reducing the selected $160^{\circ}$ to an effective window of just $140^{\circ}$. Considering the rotation increments between the parameter sets, the parameter set 1 had a greater diversity amongst consecutive layers, whereas the parameter set 2 led to a higher overlap. The findings of this study pointed towards the same direction as the investigation of Thijs, Kempen ${ }^{24}$, whereby a $90^{\circ}$ rotation increment reduced the texture. Considering the finding of Sehrt ${ }^{23}$, whereupon a $67^{\circ}$ rotation increment between layers resulted in a constant in-plane Young's modulus, it appeared that this can be related to a more arbitrary distribution of the scan tracks. In particular, changing the rotation angle increments for the applied parameter sets yields the following: The parameter set 1 with a $67^{\circ}$ 
increment results in a constant repetition after 160 layers; and the parameter set 2 returns a repetition after 90 layers respectively.

\section{Summary and outlook}

In general, widening the limitation window and larger rotation angle increments, which lower the direct overlap of the stacked scan tracks, were found to favour isotropic characteristics. Vice versa, narrowing the admissible range allows introducing distinct predominant directions. With the tested parameter sets an alteration of the Young's modulus between $151 \mathrm{GPa}$ and $208 \mathrm{GPa}$ in solid, fully-dense samples was shown, with parameter set related deviations ${ }^{1}$ in their Young's moduli of $15 \%$ and $27 \%$.

The underlying mechanism leading to this adjustable anisotropy is governed by the epitaxial grain growth of the material, i.e. secondary grain growth towards the heat source. Neighbouring scan tracks, which are fabricated afterwards lead, of course, to a secondary grain growth as well; however, as documented by Kunze, Etter ${ }^{21}$, the two distinct directions where a decreased Young's modulus is to be expected are in build direction and parallel to the scan tracks. Given this, the occurrence and emphasis of the in-plane anisotropy is highly material dependent, as the epitaxy and the melt pool dimensions are material specific ${ }^{20,36}$. Further information on the material dependency, as well as detailed micro-section evaluations can be found elsewhere ${ }^{20}$.

For future extensions of the investigations of the impact of the limitation window and the rotation angle increment the following aspects will be considered:

- Full allowance of the full window $\left(180^{\circ}\right)$, with the limitation of using unidirectional scan tracks, and thus mitigating the interference of the irradiation and transported particles in the inert gas stream.

- Utilization of prime numbers for the rotation increment to avoid repetitive patterns.

- Maximisation of the induced anisotropy via short repetitions, e.g. every third layer, to elaborate the boundaries of deliberate in-plane anisotropy in additively manufactured fully-dense components

\section{Numerical validation and estimation of expectable anisotropies in the Young's modulus:}

\footnotetext{
${ }^{1}$ Calculated with the predominant $y$-direction as basis.
} 
The progress of the work at hand strives towards the deliberate implementation of an anisotropic material behaviour based on the process conduct. The estimation of the induced level of anisotropy prior to fabrication via numerical modelling is essential for this undertaking. As of now the challenge in the modelling is the lack of the material data for the single layers. The determined characteristics represent macroscopic measures for the entirety of the stacked layers, which are crucial for the modelling of whole components fabricated with a distinct parameter set ${ }^{37}$. An initial simulation as a proof of concept was undertaken in MSC Marc 2017.0.0 based on a linear-elastic simulation of a layered prismatic model, whereby one single element height represented a distinct layer and accordingly one layer of elements was representative for one fabricated layer ${ }^{38,39}$. For the necessary linear elastic material characteristics, the results of configurations (c) and (d) were utilised and completed with the available data of related studies ${ }^{20,29}$. The sole input data of the orthotropic material model is provided in Table 5 and the obtained elastic anisotropies for a few exemplary configurations are summarised in Table 6.

On a side note, utilising these macroscopic results as input for the description of the individual layer is not accurate, and will be refined once the data for a single layer becomes available. Obtaining this data through further experiments or via approximations based on a coupled model comprising the prediction model known from welding and the circumstances in a powder bed-based environment will be the next steps ${ }^{40-44}$. Nevertheless, even this restricted preliminary model reveals how the stacking schemata of individual layers based on the selected scanning strategy impacts the in-plane anisotropy.

Table 5: Input data for the orthotropic material model; see also 20,29

\begin{tabular}{|c|c|c|c|}
\hline Direction & $\mathbf{E}_{\mathbf{1 1}} ; \mathbf{v}_{\mathbf{1 2}}$ & $\mathbf{E}_{\mathbf{2 2}} ; \mathbf{v}_{\mathbf{2 3}}$ & $\mathbf{E}_{\mathbf{3 3}} ; \mathbf{v}_{\mathbf{1 3}}$ \\
\hline Young's modulus [GPa] & 151 & 208 & 138 \\
\hline Poisson's ratio [-] & $0.3 *$ & 0.16 & 0.44 \\
\hline
\end{tabular}

* no data available, thus standard value for 1.4404 utilised

Table 6: Preliminary results for the estimation of the in-plane anisotropy

\begin{tabular}{|c|c|c|c|}
\hline Rotation angle increment $\left[{ }^{\circ}\right]$ & Limitation window $\left[{ }^{\circ}\right]$ & Ratio Ex/Ey & Experimental Ex/Ey \\
\hline 33 & 90 & 0.817 & 0.73 \\
\hline 33 & 180 & 0.986 & - \\
\hline 67 & 180 & 0.975 & - \\
\hline 90 & 160 & 0.993 & - \\
\hline 90 & 180 & 0.999 & - \\
\hline
\end{tabular}




\section{Conclusion}

In this study, the forming on in-plane anisotropy in dependency to the process conduct was studied on stainless steel tensile specimens. It was shown that slight modifications in the parameter sets, in our case amongst recommended parameter sets provided by the machine manufacturer, can significantly alter the material behaviour, even when the most commonly checked quality criteria (i.e. relative density and surface hardness) are similar. For the in-plane anisotropy it was found, that only the linear elastic properties and the breaking elongation were affected, whereas the tensile strength remained stable. Special consideration was given to the rotation angle increment of irradiation pathways of subsequent layers and the limitation window and it was showcased that these two parameters could be utilized to adjust the inherent anisotropy of additively manufactured components.

\section{Acknowledgement}

Sincere appreciation to Michael Sedlmajer, Rene Klink, and Wilfried Salzwedel for their helpful support throughout the implementation and evaluation of the experiments.

\section{Conflict of interest}

The authors declare that there is no conflict of interest.

\section{References}

1. Hitzler L, Merkel M, Hall W and Öchsner A. A Review of Metal Fabricated with Laser- and PowderBed Based Additive Manufacturing Techniques: Process, Nomenclature, Materials, Achievable Properties, and its Utilization in the Medical Sector. Adv Eng Mater. 2018; 1700658: ONLINE FIRST.

2. Bhaskaran E, Azhagarasan NS, Miglani S, Ilango T, Krishna GP and Gajapathi B. Comparative evaluation of marginal and internal gap of Co-Cr copings fabricated from conventional wax pattern, 3D printed resin pattern and DMLS tech: An in vitro study. J Indian Prosthodontist Soc. 2013; 13: $189-95$.

3. Traini T, Mangano C, Sammons RL, Mangano F, Macchi A and Piattelli A. Direct laser metal sintering as a new approach to fabrication of an isoelastic functionally graded material for manufacture of porous titanium dental implants. Dent Mater. 2008; 24: 1525-33. 
4. Yadroitsev I, Bertrand P, Antonenkova G, Grigoriev S and Smurov I. Use of track/layer morphology to develop functional parts by selective laser melting. J Laser Appl. 2013; 25: 052003.

5. Figliuzzi M, Mangano F and Mangano C. A novel root analogue dental implant using CT scan and CAD/CAM: selective laser melting technology. Int J Oral Maxillofac Surg. 2012; 41: 858-62.

6. Zhang LC, Klemm D, Eckert J, Hao YL and Sercombe TB. Manufacture by selective laser melting and mechanical behavior of a biomedical Ti-24Nb-4Zr-8Sn alloy. Scr Mater. 2011; 65: 21-4.

7. Wirtz T. Herstellung von Knochenimplantaten aus Titanwerkstoffen durch Laserformen. Fakultät für Maschinenwesen. Germany: RWTH Aachen, 2006, p. 145.

8. Cardaropoli F, Alfieri V, Caiazzo F and Sergi V. Manufacturing of porous biomaterials for dental implant applications through Selective Laser Melting. Adv Mat Res. 2012; 535-537: 1222-9.

9. Van Bael S, Chai YC, Truscello S, et al. The effect of pore geometry on the in vitro biological behavior of human periosteum-derived cells seeded on selective laser-melted Ti6Al4V bone scaffolds. Acta Biomater. 2012; 8: 2824-34.

10. Hazlehurst K, Wang CJ and Stanford M. Evaluation of the stiffness characteristics of square pore CoCrMo cellular structures manufactured using laser melting technology for potential orthopaedic applications. Mater Des. 2013; 51: 949-55.

11. Öchsner A. Continuum Damage and Fracture Mechanics. Singapore: Springer, 2016.

12. Casalino G, Campanelli SL, Contuzzi N and Ludovico AD. Experimental investigation and statistical optimisation of the selective laser melting process of a maraging steel. Opt Lasers Technol. 2015; 65: 151-8.

13. Gorny B, Niendorf T, Lackmann J, Thoene M, Troester T and Maier HJ. In situ characterization of the deformation and failure behavior of non-stochastic porous structures processed by selective laser melting. Mater Sci Eng, A. 2011; 528: 7962-7.

14. Abele E, Stoffregen HA, Kniepkamp M, Lang S and Hampe M. Selective laser melting for manufacturing of thin-walled porous elements. J Mater Process Technol. 2015; 215: 114-22.

15. Niendorf T, Leuders S, Riemer A, Richard HA, Tröster T and Schwarze D. Highly Anisotropic Steel Processed by Selective Laser Melting. Metall Mater Trans B. 2013; 44: 794-6.

16. Niendorf T, Leuders S, Riemer A, et al. Functionally Graded Alloys Obtained by Additive Manufacturing. Adv Eng Mater. 2014; 16: 857-61.

17. Riemer A, Leuders S, Thöne M, Richard HA, Tröster T and Niendorf T. On the fatigue crack growth behavior in 316L stainless steel manufactured by selective laser melting. Eng Fract Mech. 2014; 120 : $15-25$.

18. Hitzler L, Janousch C, Schanz J, et al. Direction and location dependency of selective laser melted AlSi10Mg specimens. J Mater Process Technol. 2017; 243: 48-61.

19. Hitzler L, Hirsch J, Schanz J, et al. Fracture toughness of selective laser melted AlSi10Mg. P I Mech Eng L: J Mat. 2017; ONLINE FIRST. 
20. Hitzler L, Hirsch J, Heine B, Merkel M, Hall W and Öchsner A. On the Anisotropic Mechanical Properties of Selective Laser Melted Stainless Steel. Materials. 2017; 10: 1136.

21. Kunze K, Etter T, Grässlin J and Shklover V. Texture, anisotropy in microstructure and mechanical properties of IN738LC alloy processed by selective laser melting (SLM). Mater Sci Eng, A. 2015; 620: 213-22.

22. Sehrt J and Witt G. Auswirkung des anisotropen Gefüges strahlgeschmolzener Bauteile auf mechanische Eigenschaftswerte. RTejournal 6: (2009, accessed 01/03/2016).

23. Sehrt JT. Möglichkeiten und Grenzen bei der generativen Herstellung metallischer Bauteile durch das Strahlschmelzverfahren. Maschinenbau und Verfahrenstechnik. Germany: University Duisburg-Essen, 2010 .

24. Thijs L, Kempen K, Kruth JP and Van Humbeeck J. Fine-structured aluminium products with controllable texture by selective laser melting of pre-alloyed AlSi10Mg powder. Acta Mater. 2013; 61: 1809-19.

25. Kruth JP, Deckers J, Yasa E and Wauthle R. Assessing and comparing influencing factors of residual stresses in selective laser melting using a novel analysis method. P I Mech Eng B-J Eng. 2012; 226: 980-91.

26. Kempen K, Thijs L, Van Humbeeck J and Kruth JP. Mechanical Properties of AlSi10Mg Produced by Selective Laser Melting. Physics Procedia. 2012; 39: 439-46.

27. Liebisch A and Merkel M. On the numerical simulation of the thermal behavior during the selective laser melting process. Mat-wiss $u$ Werkstofftech. 2016; 47: 521-9.

28. Roberts IA. Investigation of residual stresses in the laser melting of metal powders in additive layer manufacturing. Netherlands: University of Wolverhampton, 2012, p. 246.

29. Hirsch J. Anisotropes Materialverhalten von Edelstahl 316L beim Selektiven Laserstrahlschmelzen. Department of Mechnical Engineering. Germany: Aalen University, 2017.

30. Hitzler L, Hirsch J, Merkel M, Hall W and Öchsner A. Position dependent surface quality in Selective Laser Melting. Mat-wiss u Werkstofftech. 2017; 48: 327-34.

31. Hitzler L, Hirsch J, Merkel M and Öchsner A. Thermal environment and inclination angle dependencies on the surface quality of selective laser melted 316L steel. Defect Diffus Forum. 2017; 372: $202-7$.

32. Deutsches Institut fuer Normung e.V. DIN 50125. Prüfung metallischer Werkstoffe-Zugproben. Berlin, Germany: Beuth Verlag, 2009, p. 11.

33. Deutsches Institut fuer Normung e.V. DIN EN ISO 6507-2. Metallic Materials-Vickers Hardness Test-Part 2: Verification and Calibration of Testing Machines. Berlin, Germany: Beuth Verlag, 2016.

34. Deutsches Institut fuer Normung e.V. DIN EN ISO 6892-1. Metallic Materials-Tensile Testing-Part 1: Method of Test at Room Temperature. Berlin, Germany: Beuth Verlag, 2016.

35. ThyssenKrupp. Nichtrostender austenitischer Stahl TK 1.4404. 
36. Tang M. Inclusions, Porosity, and Fatigue of AlSi10Mg Parts Produced by Selective Laser Melting. Materials Science and Engineering. Pittsburgh, PA, USA: Carnegie Mellon University, 2017.

37. Casel M. Representative Material Model for Selective Laser Melted Materials under Consideration of Anisotropic Behaviour. Fachbereich VIII - Maschinenbau, Verfahrens- und Umwelttechnik. Gold Coast, Australia: Beuth Hochschule für Technik Berlin, Germany in cooperation with the Griffith University, Gold Coast, Australia, 2017.

38. Öchsner A and Öchsner M. The Finite Element Analysis Program MSC Marc/Mentat. Singapore: Springer, 2016.

39. Javanbakht Z and Öchsner A. Advanced Finite Element Simulation with MSC Marc. Springer International Publishing, 2017.

40. David SA and Vitek JM. Correlation between solidification parameters and weld microstructures. Int Mater Rev. 1989; 34: 213-45.

41. Trapp J, Rubenchik AM, Guss G and Matthews MJ. In situ absorptivity measurements of metallic powders during laser powder-bed fusion additive manufacturing. Appl Mater Today. 2017; 9: 341-9.

42. Qiu C, Panwisawas C, Ward M, Basoalto HC, Brooks JW and Attallah MM. On the role of melt flow into the surface structure and porosity development during selective laser melting. Acta Mater. 2015; 96: 72-9.

43. King WE, Anderson AT, Ferencz RM, et al. Laser powder bed fusion additive manufacturing of metals; physics, computational, and materials challenges. Appl Phys Rev. 2015; 2: 041304.

44. Boley CD, Khairallah SA and Rubenchik AM. Calculation of laser absorption by metal powders in additive manufacturing. Appl Opt. 2015; 54: 2477. 